\title{
Morphometric variation of extant platyrrhine molars: taxonomic implications for fossil platyrrhines
}

Mónica Nova Delgado, Jordi Galbany, Alejandro Pérez-Pérez

The phylogenetic position of many fossil platyrrhines with respect to extant ones is not yet clear. Two main hypotheses have been proposed: the layered or successive radiations hypothesis suggests that Patagonian fossils are Middle Miocene stem platyrrhines lacking modern descendants, whereas the long lineage hypothesis argues for an evolutionary continuity of all fossil platyrrhines with the extant ones. Our geometric morphometric analysis of a 15 landmark-based configuration of platyrrhines' first and second lower molars suggest that morphological stasis, may explain the reduced molar shape variation observed. Platyrrhine lower molar shape might be a primitive retention of the ancestral state affected by strong ecological constraints thoughout the radiation the main platyrrhine families. The Patagonian fossil specimens showed two distinct morphological patterns of lower molars, Callicebus -like and Saguinus -like, which might be the precursors of the extant forms, whereas the Middle Miocene specimens, though showing morphological resemblances with the Patagonian fossils, also displayed new, derived molar patternss, Alouatta- like and Pitheciinae -like, thereby suggesting that despite the overall morphological stasis of molars, phenotypic diversification of molar shape was already settled during the Middle Miocene. 
1 Morphometric variation of extant platyrrhine molars: taxonomic implications for fossil

\section{2 platyrrhines}

3 Mónica Nova Delgado, ${ }^{\mathrm{a}}$ Jordi Galbany, ${ }^{\mathrm{a}-\mathrm{b}}$ and Alejandro Pérez-Pérez ${ }^{\mathrm{a}}$

4

5 a Secció de Zoologia i Antropologia, Departament de Biologia Evolutiva, Ecologia i Ciències

6 Ambientals, Universitat de Barcelona, Av. Diagonal 643, 08028 Barcelona, Spain.

$7 \quad{ }^{b}$ Center for the Advanced Study of Human Paleobiology, Department of Anthropology, George

8 Washington University, 800 22nd Street NW, Ste 6000, Washington DC 20052, USA.

9

*Corresponding author:

Dr. Alejandro Pérez-Pérez

12

martinez.perez.perez@ub.edu

13 Tf. $+34-934021460$

14 Departament de Biologia Evolutiva, Ecologia i Ciències Ambientals, Universitat de Barcelona.

15 Av. Diagonal 645, 08028 Barcelona - Spain. 


\section{ABSTRACT}

The phylogenetic position of many fossil platyrrhines with respect to extant ones is not yet

clear. Two main hypotheses have been proposed: the layered or successive radiations hypothesis

suggests that Patagonian fossils are Middle Miocene stem platyrrhines lacking modern

descendants, whereas the long lineage hypothesis argues for an evolutionary continuity of all

fossil platyrrhines with the extant ones. Our geometric morphometric analysis of a 15 landmark-

based configuration of platyrrhines' first and second lower molars suggest that morphological stasis, may explain the reduced molar shape variation observed. Platyrrhine lower molar shape might be a primitive retention of the ancestral state affected by strong ecological constraints thoughout the radiation the main platyrrhine families. The Patagonian fossil specimens showed two distinct morphological patterns of lower molars, Callicebus-like and Saguinus-like, which might be the precursors of the extant forms, whereas the Middle Miocene specimens, though showing morphological resemblances with the Patagonian fossils, also diplayed new, derived molar patternss, Alouatta-like and Pitheciinae-like, thereby suggesting that despite the overall morphological stasis of molars, phenotypic diversification of molar shape was already settled

32 during the Middle Miocene. 


\section{INTRODUCTION}

Platyrrhine evolution is controversial. However, most researchers agree that they most likely constitute a monophyletic clade derived from African ancestors (Fleagle and Kay, 1997; Takai et al., 2000; Kay et al., 2004; Oliveira et al., 2009; Bond et al., 2015), although the phylogenetic position of some living taxa and the affinities of some fossil specimens are still uncertain. Currently, two different viewpoints have been proposed regarding the evolutionary history of the earliest platyrrhines and their overall relationships with extant forms. The "long lineages" hypothesis argues that the oldest known Patagonian fossils (16-20 Ma) are to be included within the extant Platyrrhines (Rosenberger, 1979, 1980, 1981, 1984; Rosenberger et al., 2009; Tejedor, 2013), whereas the "layered or successive radiations" hypothesis suggests that these fossils constitute a geographically isolated stem group, phylogenetically unrelated to the crown platyrrhines, that went extinct (along with some Antillean species) (Kay, 2010; 2014; Kay and Fleagle, 2010; Kay et al., 2008). According to Kay (2014), the divergence of modern lineages occurred in the tropics. The Late Oligocene and Early Miocene platyrrhines would have branched off from the ancestral lineage when climatic conditions in Patagonia became unfavorable and the Andean uplift was a potential barrier to their dispersal. However, Tejedor (2013) has suggested that Chilecebus (20 Ma), a fossil specimen (Tejedor, 2013) from the western Andean cordillera, south of Santiago de Chile, indicates that the Andean mountains did not constitute a biogeographic barrier. Tejedor (2013) argued that a paleobiogeographic corridor throughout western South America would have allowed for a continental connectivity between the north and the southernmost fossil platyrrhines. Unfortunately, dating of the fossil specimens and fossil-based approaches for calibrating the molecular phylogeny support both models. Perez et al. (2013) have estimated a crown platyrrhine origin at around $29 \mathrm{Ma}$ (27-31), which allows 
57 for the inclusion of the fossil Patagonian primates into a crown Platyrrhini lineage showing

58 evolutionary continuity with the Middle Miocene lineages. In contrast, Hodgson et al. (2009)

59 have dated their origin between 16.8 and 23.4 Ma, suggesting an unlikely relationship of the

60 early Miocene fossils with the crown platyrrhine clade (but see different temporal models in

61 Goodman et al., 1998; Opazo et al., 2006; Chatterjee et al. 2009; Perelman et al. 2011; Wilkinson

62 et al. 2011; Jameson Kiesling et al. 2014).

63 Molar morphology has been widely used to determine the phylogenetic positions of extinct

64 specimens with respect to living forms (e.g., Kay, 1990; Rosenberger et al., 1991a, b; Benefit,

65 1993; Meldrum and Kay, 1997; Miller and Simons, 1997; Horovitz and MacPhee, 1999; Kay and

66 Cozzuol, 2006; Kay et al., 2008), since tooth development is under strong genetic control

67 (Jernvall and Jung, 2000). Recent studies have reported that molar shapes carries strong phylogenetic signals, and can be useful tool for establishing taxonomic affinities between extanct and extinct catarrhine primates (Nova Delgado et al., 2015a; Gamarra et al., 2016), and also in some Platyrrine taxa (Nova Delgado et al., 2015b), with closely related species exhibiting common phenotypic traits.

\section{Affinities of the fossil platyrrhine primates based on dental morphology}

Until now, a total of 31 Early Miocene Platyrrhini fossil genera have been so far reported in the South American continent and the Caribbean: 13 in La Venta (Colombia), 8 in the Argentinian Patagonia, 5 in the Greater Antilles, 5 in Brazil, and 1 each in Chile, Bolivia and Peru (Tejedor, 2013; Bond et al., 2015). Neosaimiri, Laventiana (La Venta, Colombia) and Dolichocebus (Chubut Province, Argentina) have been included in Cebinae (Rosenberger, 2011).

Neosaimiri is considered a direct ancestor of the extant Saimiri due to its similar molar shape 
80 (Rosenberger et al., 1990a; 1991a). Its molars exhibit sharp cusps, well-developed distal cusps,

81 buccal cingulum, a strong buccal flare, and a distinct post-entoconid notch on molars only found

82 in Saimiri and Laventiana (Rosenberger et al., 1991a, 1991b; Takai, 1994; Tejedor, 2008).

83 Laventiana is sometimes considered a synonym of Neosaimiri (Takai, 1994; Meldrum and Kay,

84 1997), although it has been suggested to be more primitive than Neosaimiri (Rosenberger et al., 1991b). Laventiana's teeth closely resemble those of Saimiri and Cebus-Sapajus; it shows thickenamel bunodont molars exhibiting a small buccal cingulum and an angular cristid obliqua, lacking buccal flare (Rosenberger et al., 1991b). Dolichocebus has been suggested to be a member of the Saimiri lineage, mainly for its interorbital fenestra considered a derived feature in squirrel monkeys (Tejedor, 2008; Rosenberger et al., 2009; Rosenberger, 2010). However, Kay and colleagues (Kay et al., 2008; Kay and Fleagle, 2010) argued that Dolichocebus is a stem platyrrhine and that the description of the orbital region was probably affected by postmortem damage.

On the other hand, Aotus dindensis was first described as a sister taxon of extant Aotus (Setoguchi and Rosenberger, 1987), although Kay (1990) has suggested that it is probably conspecific with Mohanamico hershkovitzi, which may be closely related to the callitrichines, especially Callimico, due to their morphological similarities in the canine and the second premolar. Aotus dindensis is included into the Pitheciidae (Rosenberger et al., 1990a) within the Homunculinae subfamily, along with Aotus, Callicebus and some Argentinian and Caribbean fossil primates (Rosenberger, 1981, 2002, 2011). However, molecular phylogenetic analyses have repeatedly rejected a link between Aotus and Pitheciids (.e.g Hodgson et al., 2009;

Osterholz et al., 2009; Wildman et al., 2009), placing it as a basal cebid. Tejedor and Rosenberger (2008) proposed that Homunculus is likely an ancestral pitheciid because although 
103 it shows a primitive dental morphology, it notably resembles that of Callicebus. The two taxa

104 show rectangular-shaped molars, small incisors and non-projecting canines, a trait shared with

105 Carlocebus (Fleagle, 1990). Nonetheless, unlike Callicebus, the molars of Homunculus exhibit

106 well-marked crests and prominent cusps (Tejedor, 2013), and an unusual paraconid on the lower

107 first molar (also found in Dolichocebus; Kay et al., 2008). Another fossil from the early Miocene

108 known as Soriacebus was initially included by Rosenberger (1990) as an early Pitheciinae, due

109 to its resemblance on the anterior dentition (Fleagle et al., 1987; Fleagle, 1990; Fleagle and

110 Tejedor, 2002; Tejedor, 2005). However, some dental traits of Soriacebus (premolars-molars

111 size, lower molar trigonid, and reduction hypocone) bear resemblance also with the

112 callitrichines. Indeed, Kay (1990) argues that such similarities traits found between Soriacebus

113 and pitheciines or with callitrichines are due to homoplasy, rather than phylogenetic relationships

114 among such lineages (Kay, 1990). According to Kay (1990), Soriacebus, Carlocebus,

115 Homunculus and all Patagonian fossils should be considered stem platyrrhines.

116 Xenothrix is a Late Pleistocene Caribbean fossil from Jamaica that shows a callitrichine-like

117 dental formula (2132; MacPhee and Horovitz, 2004), low relief molars and a narrowing of

118 intercuspal distance and augmentation of the mesial and distal crown breadths (Cooke et al.,

119 2011), a feature also seen in Insulacebus toussaintiana, another Caribbean primate. Rosenberger

120 (2002) argued that Xenothrix is closely related to Aotus and Tremacebus by the enlargement of

121 the orbits and the central incisors, while MacPhee and Horovitz (2004) suggested a possible

122 Pitheciidae affinity, due to its low relief molar pattern. Nonetheless, the puffed cusps and the

123 lack of crenulation on the molar crown discriminate the Jamaican fossil from the Pitheciidae,

124 suggesting that is likely that Xenothrix does not belong to crown platyrrhine group (Kay, 1990;

125 Kinzey, 1992). 
with the extant Pitheciidae family, mostly in the anterior dentition but also in their low molar cusps and poorly developed crests (Kay, 1990; Meldrum and Kay, 1997). Nuciruptor does not exhibit several of the shared traits among pitheciines (projecting canine and small or absent Kay 1997), was interpreted by Meldrum and Kay (1997) as an example of convergent evolution, and thus, not a direct ancestor of extant pitheciines. Finally, Stirtonia (originally from Colombia but also recovered from Acre State, Brazil) exhibits similar dental size and morphology to extant Alouatta; showing molar teeth with sharp and well-formed crests, a long cristid oblique, small trigonid, and spacious talonid basin (Hershkovitz, 1970; Kay et al., 1987; Kay and Frailey, 1993; Kay and Cozzuol, 2006; Kay, 2014). shape for studying patterns of inter-specific variation and their implication in phylogeny and ecological adaptations (e.g., Bailey, 2004; Cook, 2011; Gómez-Robles et al., 2007, 2008, 2011; Martinón-Torres et al., 2006; Singleton et al., 2011; White, 2009; Nova Delgado et al., 2015a,b; Gamarra et al., 2016). However, in Platyrrhine primates, GM of molar shape has mainly focused on dietary adaptations (Cooke, 2011), rather than to predict the phylogenetic attribution of unclassified specimens (Nova Delgado et al., 2015a).

144 The aim of the present study is to use two-dimensional (2D) GM to quantify and analyze occulsal shape variation of lower molars $\left(\mathrm{M}_{1}\right.$ and $\left.\mathrm{M}_{2}\right)$ of extant Platyrrhini primates to asesses the affinities of the Patagonian, Colombian, and Antillanean fossil taxa with the extant forms and to estimating the efficiency of molar shape for discriminating fossil specimens. 
149

150

151

152

153

154

155

156

157

158

159

160

161

162

163

164

165

166

167

168

169

170

171

\section{MATERIAL AND METHODS}

Images of the dental crowns, in occlusal view and including a scale line, of 12 holotypes

fossil platyrrhine specimens and one fossil from Fayum (Proteopithecus sylviae), were obtained from the literature (Table 2). The platyrrhine fossil specimens included 12 genera (Soriacebus, Dolichocebus, Homunculus, Carlocebus, Neosaimiri, Laventiana, Mohanamico, Aotus, Stirtonia, Nuciruptor, Cebupithecia, and Xenothrix), discovered in Argentina, Colombia, and Jamaica, and dated to between Holocene and early Miocene (Table 1).

The extant comparative samples consisted in 802 adult individuals representing all recognized platyrrhine groups (3 families, 18 genera, 61 species; Table 2), whose 2D and 3D morphometric variability of lower molars has alredy been analysed in some platyrrine species (Nova Delgado et al., 2015b). Dental casts were obtained from original specimens housed at Museu de Zoologia Universidade de São Paulo (MZPS), Museu Nacional do Rio de Janeiro (MNRJ) in Brazil, and from Hacienda La Pacífica (HLP) in Costa Rica. The casts were made following published protocols (see Galbany et al., 2004, 2006). 2D images of molar occlusal surfaces of the extant specimens were taken with a Nikon D70 digital camera fitted with a 60$\mathrm{mm}$ optical lens held horizontally on the stand base, at a minimum distance of $50 \mathrm{~cm}$. The dental crown was imaged with a $0^{\circ}$ of tilt with the cervical line perpendicular to the camera focus (Nova Delgado et al., 2015a). Images of fossil dental crowns were obtained from the literature and imported to Adobe Photoshop, where they were scaled to the same resolution (400 dpi). The images both for the extant and the fossil specimens were scaled to $5 \mathrm{~mm}$ and standardized to right side, with the mesial border facing to the right, the distal border to the left, and the lingual and buccal sides facing upward and downward, respectively. All images were saved at high resolution $(1600 \times 1200$ pixel $)$ in JPEG format. 


\section{Geometric morphometric analysis}

Geometric Morphometrics (GM) quantifies shape differences between biological

175 structures using a set of digitized homologous points (landmarks) in two-dimensional or three-

176 dimensional spaces (Bookstein 1991; Adams et al. 2004; Slice 2005). Landmarks are numerical

177 values (coordinates) that reflect the location and orientation of each specimen in the

178 morphospace (Slice, 2007). A previously defined two-dimensional (2D) landmark protocol

179 (Nova Delgado et al., 2015a, b; Gamarra et al., 2016) was adopted. The configuration consisted 180 of 15 landmarks. Molar occlusal polygon was defined by the tips of the four main cusps

181 (protoconid, metaconid, hypoconid, and entoconid). The crown outline was represented by eight

182 landmarks, which included two landmarks on fissure intersections; four corresponding to

183 maximum crown curvatures; and two in the mid mesio-distal line on the crown perimeter.

184 Further, three landmarks were used to represent the positions of crests (Table 3 and Fig. 1)

185 (Cooke, 2011). Landmark recording was performed with TPSDig v 1.40 (Rohlf, 2004) and

186 landmark coordinates were then imported into MorphoJ (Klingenberg, 2011). The most

187 commonly employed method to remove the information unrelated to shape variation is the 188 generalized procrustes analysis (GPA) (Rohlf, 1999, 2005). GPA is based on a least squares

189 superimposition approach that involves scaling, translation and rotation effect so that the 190 distances between the corresponding landmarks are minimized (Rohlf and Slice, 1990; Goodall, 191 1991; Rohlf and Marcus 1993; Rohlf, 1999; Adams et al., 2004).

192 Intra-observer landmark digitizing error was measured in a subsample of 5 specimens 193 representative of 5 different species including one fossil taxon (Alouatta belzebul, Aotus 194 dindensis, Callicebus personatus, Callithrix geoffroyi, Pithecia irrorata). The landmarks were 
195 digitized nine times during three non-consecutive days. Mean Procrustes distance between paired 196 repetitions was 0.13328 , with a standard deviation of 0.04644 , and the average Pearson

197 correlation between Procrustes distance matrices (Mantel test) of the repeated measurements was 198 0.9887. No significant differences in shape configurations among repetitions were obtained with 199 a non-parametric MANOVA (Anderson, 2001): $\mathrm{F}=0.07729 ; \mathrm{P}=0.9997)$. The inter-observed 200 error rates were not computed since a single researcher (MND) made all the analyses.

201

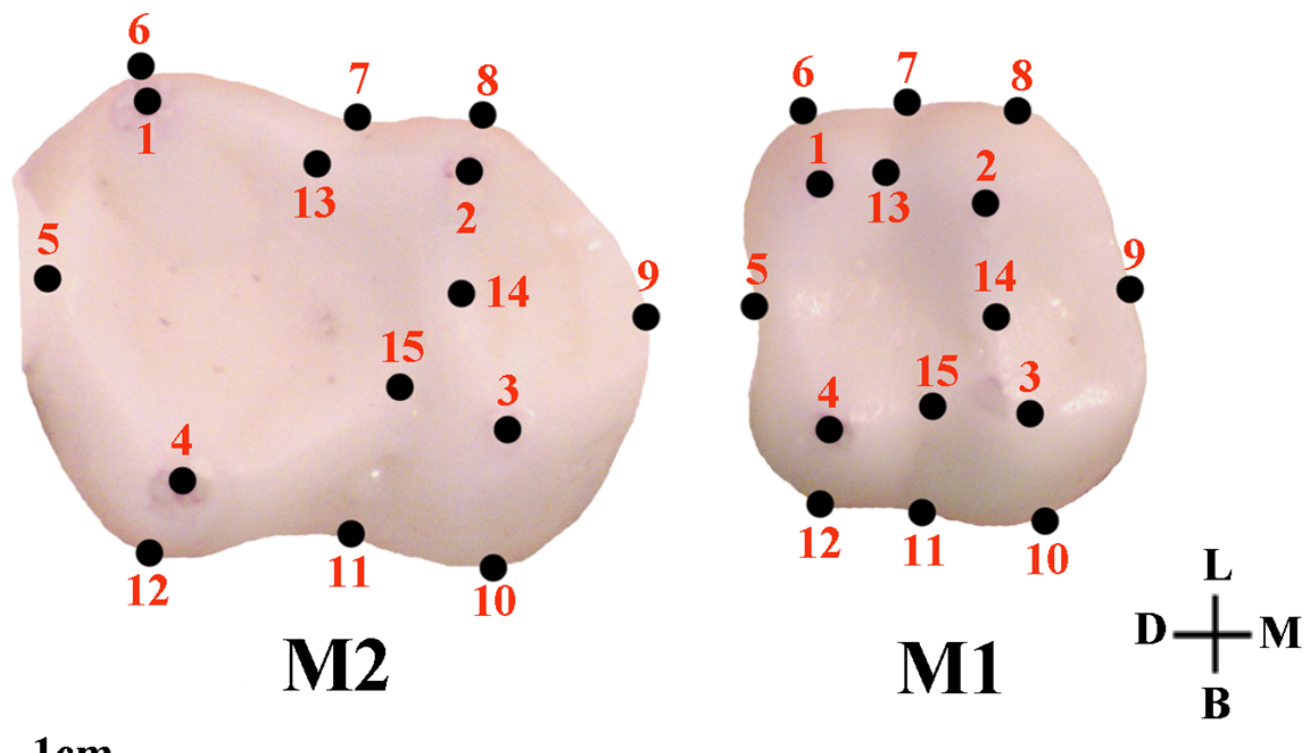

202

203 Figure 1. Set of landmarks used in the geometric morphometrics analyses. a) $\mathrm{M}_{2}$; Alouatta 204 guariba 23177 MNRJ; b) M : Sapajus libidinosus 23246 MNRJ.

After the procrustes superimposition, the covariance matrix of all the compared shapes was used to derive a Principal Components Analysis (PCA) (Zelditch et al., 2004). The PCA of $\mathrm{M}_{1}$ and $\mathrm{M}_{2}$ morphometric variability of the extant species were used to explore phenetic dental 209 similarities of fossil specimens within the extant comparative platyrrhine sample. The resulting 
210 PCA scores were used to conduct a Linear Discriminant Function analysis (LDA) to classify

211 fossil specimens, since PCA removes the irrelevant and redundant dimensions (Zelditch et al.,

212 2004). LDA maximizes differences between groups but allows classifying isolated cases based

213 on their distances to the group centroids of the extant taxa. The probability that a case belongs to

214 a particular group is proportional to the distance to the group centroid (Kovarovic et al., 2011).

215 The reliability of the classification was estimated from the post-hoc correct classification

216 probability after cross-validation $(p c c)$, and the a posteriori probability score was used as the

217 probability that a fossil belongs to a particular group. Several LDAs were made considering

218 different discriminant factors: 1) family (Cebidae, Atelidae, Pitheciidae), 2) the subfamily-level

219 classification proposed by Groves (2005) (Subfamily G) (Cebinae, Saimiriinae, Callitrichinae,

220 Pitheciinae, Callicebinae, Aotinae, Atelinae, Alouattinae), 3) the subfamily classification by

221 Rosenberger (2011) (Subfamily R) (Cebinae, Callitrichinae, Pitheciinae, Homunculinae,

222 Atelinae) (Table 4), and 4) a genus level (Cebus, Sapajus, Saimiri, Callithrix, Mico, Cebuella,

223 Callimico, Leontopithecus, Saguinus, Aotus, Callicebus, Cacajao, Chiropotes, Pithecis,

224 Lagothrix, Brachyteles, Atelles, Allouatta). The LDA analyses were carried out with SPSS v.15

225 (SPSS, Inc. 2006).

226

\section{RESULTS}

\section{Principal components analyses}

229 The first two PCs of the PCA analysis of $\mathrm{M}_{1}$ for all platyrrhines (Fig. 2) explain $42.06 \%$ of 230 total shape variance (PC1 30.60\%; PC2 11.46\%). Positive scores on PC1 correspond to molars 231 with a broad occlusal polygons and a mesiodistally rectangular outline; whereas a negative PC1

232 score are characterized by a relatively quadrangular outline and slight buccolingually rectangular 
233 occlusal polygon resulted by displacement of distal cusps (entoconid and hypoconid) to mesio-

234 lingually and mesial cusps (metaconid and protoconid ) to distal-lingually side respectively.

235 Positive scores on PC2 molar indicate a rectangular occlusal polygon and a mesiodistally

236 rectangular outline, whereas negative score on PC2 reflect molars with relatively quadrangular

237 outline and slight rectangular occlusal polygon more widely displaced to buccally side.

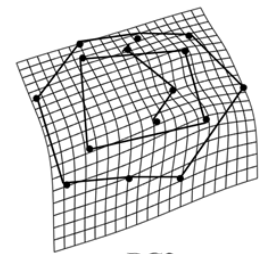

$\mathrm{PC2}+$
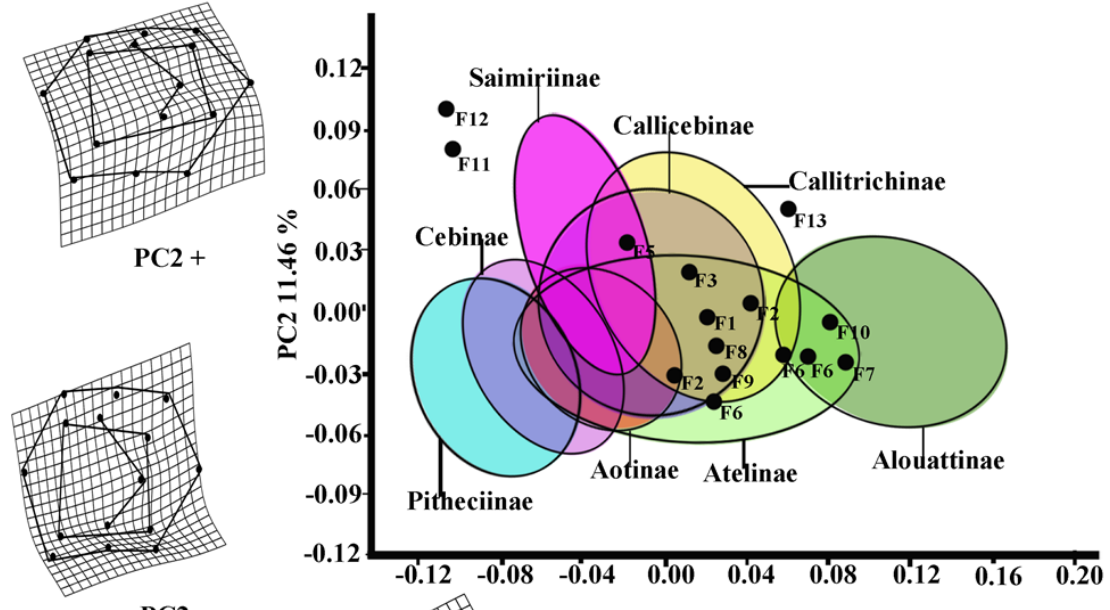

PC2 -

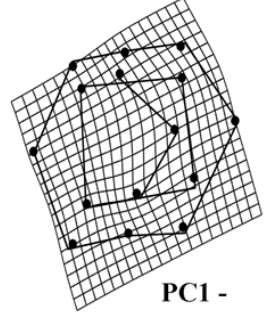

PC1 $30.60 \%$

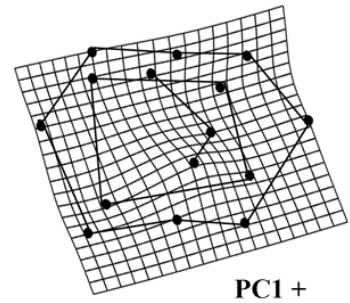

241 Figure 2. Scatterplot of the first two principal components (PCs) derived from the PCA of $\mathrm{M}_{1}$

242 shape variability of Platyrrhini. Grids indicate the deformations associated with the extreme values of each principal component. Ellipses represent the subfamily-level classification

244 proposed by Groves (2005). The letters F and numbers in figure represent the fossils listed in 245 Table 1. 
Even though the PCA does not distinguish subfamilies, the plot of PC1 versus PC2 (Fig.

2, including $95 \%$ confidence ellipses of the subfamily groups) shows clear trends between subfamilies. Alouattinae clearly cluster on the positive scores of PC1, while Pithecinae and Cebinae greatly overlap on the most negative score of PC1. The rest of the groups (Saimirinae, Callicebinae, Callitrichidae, Atellidae, and Aotinae) show intermediate values for PC1 and greatly overlap. For the second PC function (PC2), all groups greatly overlapp, though Saimirinae, Callitrichinae and Callicebinae show somewhat higher PC2 scores than the rest. Most of the fossil specimens showed positive PC1 scores, except Carlocebus (F5) and especially Nuciruptor (F11) and Cebupithecia (F12) that had negative PC1 and positive PC2 scores. Most extinct forms overlapped with the extant platyrrhines, within Callicebinae, Callitrichinae, and Atellinae, except Xenothrix (F13), Nuciruptor and Cebupithecia, which do not. PC2: $14.22 \%$ ). The molar shape changes for positive and negative PC1 scores for $\mathrm{M}_{2}$ were relatively similar to those observed for $\mathrm{M}_{1}$, whereas positive PC2 scores for $\mathrm{M}_{2}$ corresponded to the negative ones on PC2 for $\mathrm{M}_{1}$, and negative ones on PC2 for $\mathrm{M}_{2}$ were equivalent to the positive score of PC2 for $\mathrm{M}_{1}$. The PC1 versus PC2 plot (Fig. 3) showed similar distributions of the subfamilies to those for $\mathrm{M}_{1}$, although greater separations between groups were observed. Alouattinae showed the largest, positive scores for PC1, and Pitheciinae and Cebinae the most negative scores, with the other groups showing again intermediate values. Callitrichinae and Saimiriiane were placed mainly on the negative score of the PC2 axis, although they overlapped somewhat with the other groups. Most fossil specimens again clustered on positive scores for PC1 and PC2, mainly within the dispersion of Callitrichinae, although Stirtonia (F10), and some specimens of Neosaimiri clearly fell within the Alouattinae clade, Dolichocebus (F3) within 
270 Saimiriinae, and Nuciruptor (F11) was closer to Cebinae and Pitheciinae on the negative scores

271 of PC1. Homunculus (F4) did not fell at all within any extant taxa, showing highly possitive PC2

272 scores.

273

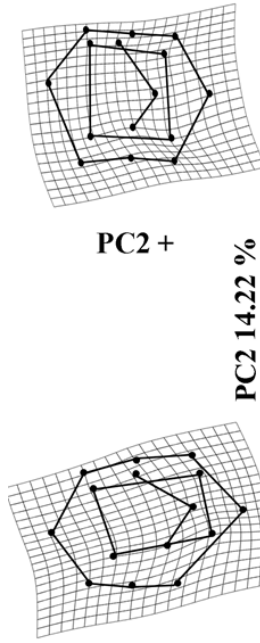

PC2 -

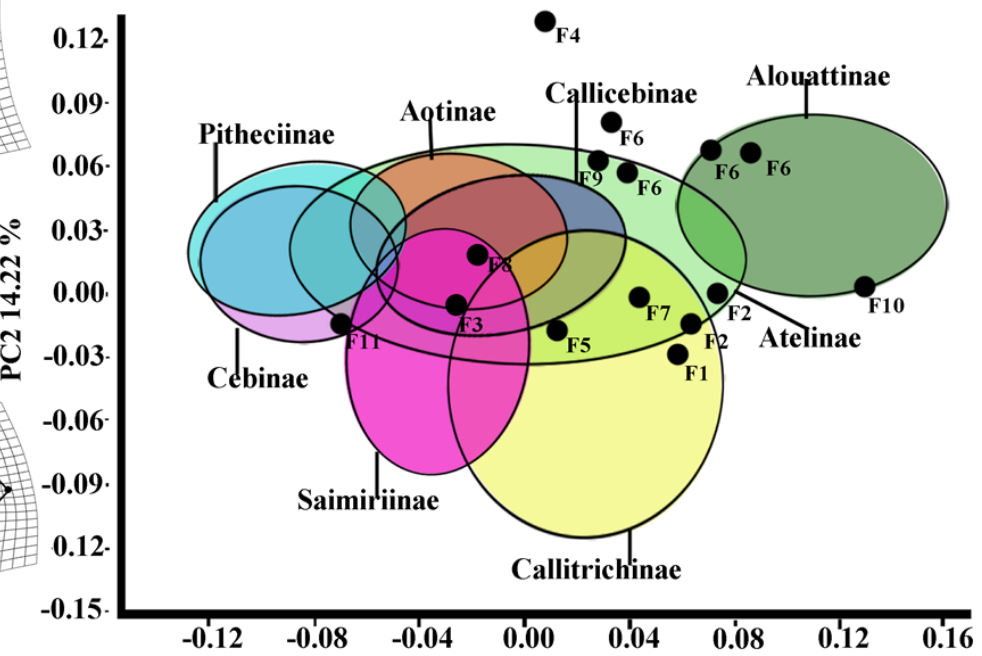

a

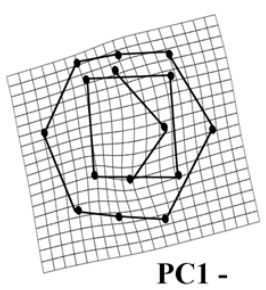

PC1 $28.58 \%$

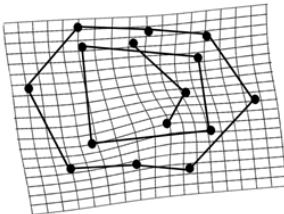

PC1+
274

275

276

277

278

279

280

281

282

Figure 3. Scatterplot of the first two principal components (PCs) derived from the PCA of $\mathrm{M}_{2}$ shape variability of Platyrrhini. Grids indicate the deformations associated with the extreme values of each principal component. Ellipses represent the subfamily-level classification proposed by Groves (2005). The letters F and numbers in figure represent the fossils listed in Table 1.

\section{Discriminant analyses of the fossil speciomens}

The post-hoc percentages of correct classification after cross-validation ( $p c c)$ were high both for $\mathrm{M}_{1}($ Table $4 \mathrm{a}$, range $=[85.7-88.0 \%])$ and $\mathrm{M}_{2}($ Table $4 \mathrm{~b}$, range $=[84.7-90.6 \%])$. In both 
283 cases the highest $p c c$ value was obtained when Groves' subfamily factor was discriminated. The 284 range of differences between $p c c$ values before and after cross-validation was [1.3-4.7] and in 285 both teeth the genus discrimiant factor showed the highest decrease in $p c c$. The difference in $p c c$ 286 values between Groves' (Cebinae, Saimiriinae, Callitrichinae, Pitheciinae, Callicebinae, Aotinae, 287 Atelinae, Alouattinae) and Rosenberger's (Cebinae, Callitrichinae, Pitheciinae, Homunculinae, 288 Atelinae) $p c c$ values were $2.3 \%$ for $\mathrm{M}_{1}$ and $1.6 \%$ for $\mathrm{M}_{2}$ (Table 5). The percentage of total 289 variance explaine by the first two discriminant functions (DF1, DF2; Table 4) for all discriminat 290 factors ranged from $63.3 \%$ (genus) to $100 \%$ (family) for $\mathrm{M}_{1}$, and from $66.1 \%$ (genus) to $100 \%$ 291 (family) for $\mathrm{M}_{2}$. The highest percentage of total variance explained by DF1 was 56.0\% (family) 292 for $\mathrm{M}_{1}$ and $68.3 \%$ (family) for $\mathrm{M}_{2}$, and the highest one for DF2 was $44.0 \%$ (family) for $\mathrm{M}_{1}$ and $29332.8 \%($ subfamily $R)$ for $\mathrm{M}_{2}$.

294 Regarding the classification of the fossils specimens, the ranges of the a priori classification probabilities varied depending on the discriminant factor used (Table 5; Fig. 4 shows the landmark configurations of the fossil specimes analysed). Mohanamico showed a high probability of belonging to the callitrichines clade, as well as Carlocebus, although the probability was smaller for $\mathrm{M}_{2}$. Both Neosaimiri and Soriacebus showed high probabilities of belonging to the callitrichines for $\mathrm{M}_{1}$, though to Callicebinae/ Homunculinae for $\mathrm{M}_{2}$. Cebupithecia $\left(\mathrm{M}_{2}\right.$ not available) and Nuciruptor neotypes showed a high probability of belonging to the pitheciid clade in LDAs. In contrast, Xenothrix $\left(\mathrm{M}_{2}\right.$ not available) likely belonged to Callithrix, despite in the PCA this fossil specimen did not fall within Callitrichinae range. Stirtonia was assigned to the Atelidae clade, and to Alouatta at the genus level, except for Rosenberger' subfamily factor for $\mathrm{M}_{2}$. Laventiana was also classified into the atelids for $\mathrm{M}_{1}$, but was more closely related to callitrichines for $\mathrm{M}_{2}$. Aotus dindensis showed a high probability of 
306 belonging to Aotus taxa for $\mathrm{M}_{1}$, but Callicebus was the group with the greatest affinity for $\mathrm{M}_{2}$.

307 Finally, Proteopithecus showed a high resemblance with Saimiri for $\mathrm{M}_{1}$, but with Callimico for $308 \mathrm{M}_{2}$

309

310

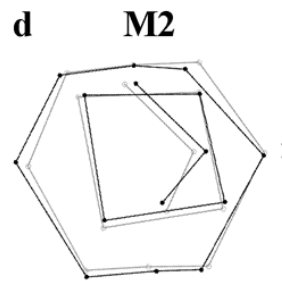

Carlocebus

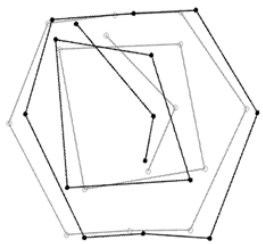

Homunculus

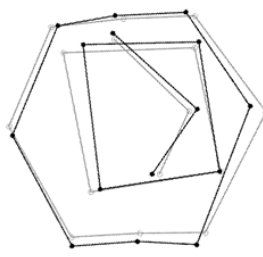

Nuciruptor

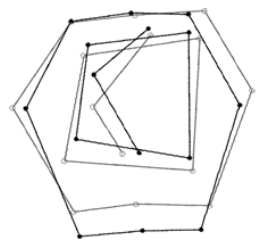

Cebupithecia

M1

Xenothrix
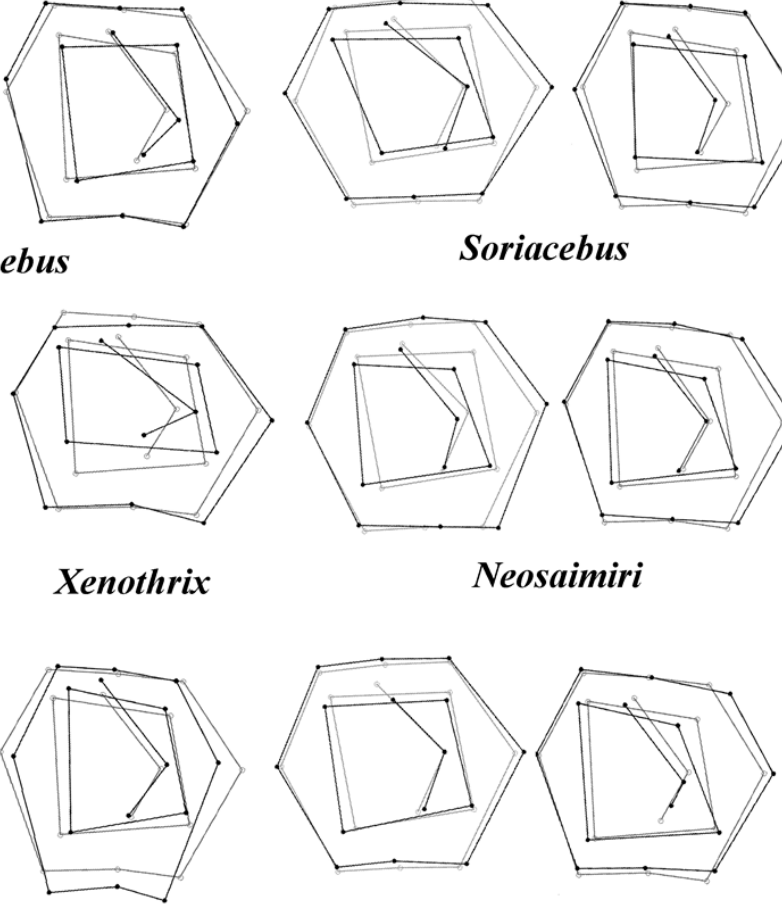

Laventiana

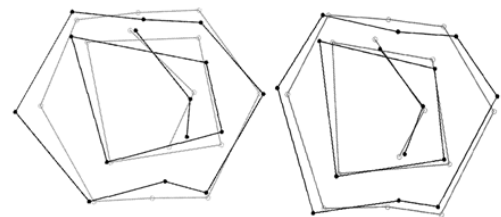

Stirtonia

M1

Soriacebus

Neosaimiri
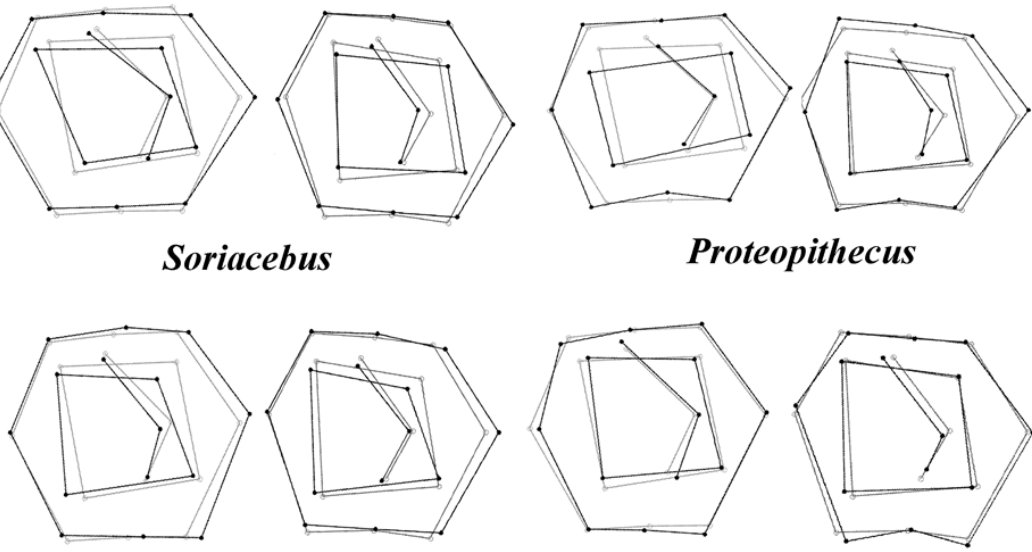

Dolichocebus
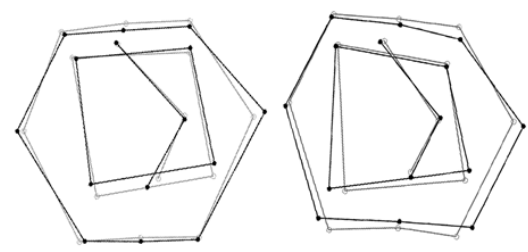

Mohanamico

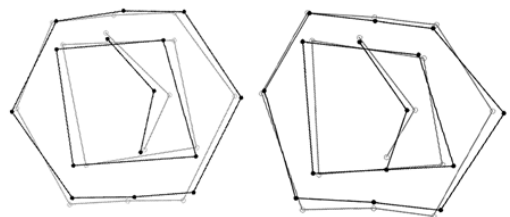

Aotus dindensis

311

312

Figure 4. Firts and second molar shapes of the extinct fossil platyrhines used in this study. 


\section{DISCUSSION}

The positions of the anthropoid form Proteopithecus sylviae (F1) in the morphospace and its molar shapes showed pattern resemblance to that of platyrrhines. However, because, many dental and postcranial features of $P$. sylviae are considered to be symplesiomorphic characters of all anthropoids, it is placed as the stem anthropoid (Kay, 1990, 2014). The recent discovery of Perupithecus ucayaliensis, probably from the Late Eocene, suggests that this fossil exhibits similarities with Proteopithecus, also with Talahpithecus and Oligopithecidae (Bond et al., 2015). The upper molars of Perupithecus slightly resemble those of the callitrichines, but its morphology is more similar to Proteopithecus and Talahpithecus (Bond et al., 2015).

Proteopithecus sylviae differed from the extant and extinct platyrrhines in having a molar distomesially expanded, marked by a rectangular shape of the occlusal polygon (especially on $\mathrm{M}_{2}$ ) (also seen in Xenothrix). Thus, if the Fayum form likely was a sister taxon to platyrrhines, the interspecific variation of shape would have shown relatively little change. This could mean that the main traits of molars shapes in platyrrhines represent retention of a primitive ancestral form. Moreover, the LDA showed a high probability of $P$. sylviae belonging to the Cebidae clade, suggesting that the molar of the earliest ancestors of platyrrhines must have exhibited close similarity to Saimiri-Callimico. This resemblance matches with the description of an Oligocene primate fossil found in South America, Branisella (Rosenberger, 2002; Rosenberger et al., 2009), whose morphology indicates that the structural characteristics of $\mathrm{M}_{2}$ may have been

335 Saimiri-like, and the upper $\mathrm{P}^{2}$ a Callimico-like (Rosenberger, 1980). However, both molar shapes of P. sylviae more closely resembled Callimico than Saimiri. Furthermore, the subtriangular upper molars of Perupithecus, show relative similarity with Callimico (Bond et al., 2015). Thus, 
338 if $P$. sylviae was a sister taxon of platyrrhines, is likely that the hypothetical ancestral molar

339 shape of pre-platyrrhine would have been similar to a molar of Callimico. By contrast, if $P$.

340 sylviae were a stem species, Callimico would show retention of primitive pre-anthropoid

341 platyrrhine molar shape.

342

343 Early Miocene platyrrhines from Patagonia

344 Most of the traits used to identify phylogenetic affinities among Early Miocene platyrine

345 fossils show high levels of homoplasy (Kay $(1990,2010,2014)$. The present work alone cannot

346 reject the successive radiations or the long lineages hypotheses, nor can confirm which is correct.

347 However, the PCA showed clear trends at the subfamily level (Fig. 2 and 3). Although the fossils

348 were not very spread out in the morphospace, many of them were located mainly within the

349 Callicebinae and Callitrichinae range (except to Homunculus for $\mathrm{M}_{2}$ ), showing phenetic

350 similarities with these two extant subfamilies

351 The Early Miocene fossils were mainly assigned to two taxa by the LDA; a Callicebus-

352 shaped and a Sagunus- shaped. For example, Dolichocebus (F3) was classified as a pitheciid,

353 mainly by having a square occlusal polygon (Table 4). However, although the PCA for $\mathrm{M}_{1}$

354 placed this specimen in the Callicebinae range, a morphological similarity with Saimiriinae was

355 seen for $\mathrm{M}_{2}$ (Fig. 3a). In contrast, Soriacebus (F2) was related mainly to the callitrichine clade,

356 but for $\mathrm{M}_{2}$ the probability of belonging to this group was small (Table 4). Because, Soriacebus

357 showed a rectangular occlusal polygon on $\mathrm{M}_{2}$ and the ectoconid was inclined distolingually.

358 Regarding callitrichines, although Soriacebus also showed differences in cusp configuration, the

359 callitrichines and Soriacebus share a C-shaped distal side and a somewhat straight lingual-side

360 contour (mostly seen in Saguinus). Kay (1990) reported that many dental features of marmosets 
361 and Soriacebus were convergent. In contrast, Rosenberger et al. (1990b) suggested that there are

362 some similarities with callitrichines (development of hypoconids and entoconids in the talonid),

363 although, based on the anterior teeth, they concluded that Soriacebus represents the first branch

364 of pitheciines. Although marmosets are considered derived lineages (e.g. Chatterjee et., 2009;

365 Perelman et al., 2009; Jameson Kiesling et al., 2014), it is likely that the relation with Soriacebus

366 may be due to the fact that callitrichines exhibit primitive traits on their molars, which means

367 that both taxa share a retention of rectangular contour and occlusal polygon shape. In the case of

368 Carlocebus (F5), it was classified as a Callitrichinae in the DFA. However, it has been shown to

369 be more similar with Callicebus than marmosets, such as the shape contour and quadrate

370 alignment of cusps in both molars. Homunculus (F4), was placed outside the range of Patagonian

371 forms in the PCA (Fig. 2a), whereas the LDA indicated a high probability of belonging to

372 Pitheciidae (ca. 91-99\%; Table 4), and especially to Calliecebus. Nonetheless, Homunculus

373 molar showed an asymmetrical shape compared to pitheciid forms. Furthermore, unlike

374 pitheciids, Homunculus cusps were predominantly inclined toward the distal side and the

375 trigonid was almost as broad as the basin-like talonid, which means that although sharing some

376 traits with pitheciids, its position is highly uncertain.

\section{Middle Miocene platyrrhines from Colombia and the Caribbean Xenothrix}

379 Many of these fossils were mostly catalogued as callitrichines, specifically into the Saguinus

clade, except Nuciruptor, Cebupithecia, Aotus dindensis, and Stirtonia. One of the major

differences between these primates and the extant forms (excep Alouatta and Brachyteles) was

the rectangular-shaped molar (see Xenothrix below). This phenetic similarity among phyletically 
384 represents a plesiomorphy in the Patagonian fossils. Thus, the trend toward ovoid molar shape

385 might be a derived feature in many living forms. Laventania (F7) exhibited distally oriented

386 cusps on $\mathrm{M}_{1}$, showing considerable resemblance with some atelid groups, which provided a

387 confusing classification between atelids and Callicebus in the LDA (Table 5). Thus, the trend to

388 rectangular shape for $\mathrm{M}_{1}$ in Laventania differs notably from the phylogenetic relationship with

389 Cebinae and Saimiriinae. Nonetheless, when $\mathrm{M}_{2}$ was analyzed, the fossil was classified as

390 member of the Callitrichinae clade. As with Laventania, some neotypes of Neosaimiri (F6) were

391 classified in completely distant taxonomic groups (Table 4). However, despite these results,

392 Neosaimiri was principally associated to the Cebidae family, although the molar shape was

393 found to have more affinities with callitrichines than Saimiri. On the other hand, Mohanamico

394 (F8) and Aotus dindensis (F9) have been considered by Kay and collaborators (Meldrum and

395 Kay, 1997; Kay 2014) to belong to the same genus, despite Takai et al. (2009) have suggested

396 that $A$. dindensis should be assigned to distinct genus. According to their molar shape,

397 Mohanamico and A. dindensis may be classified into different species. Both fossils showed a

398 relative rectangular shape of the outline, as well as in the occlusal polygon, although $\mathrm{M}_{2}$ in both

399 species was slightly square shaped. In fact, PCA for $\mathrm{M}_{1}$ (Fig. 2a) showed that the two forms were

400 placed closer to each other. Thus, similar molar shape might be due to the fact that the two forms

401 must have shared relatively similar ecological niches, likely because Mohanamico and $A$.

402 dindensis were found in the same locality and at the same stratigraphic level (Kay, 1990).

403 However, the LDA indicated that the probability of classification was different for both groups.

404 Aotus dindensis was mainly related to Aotus/Callicebus, whereas Mohanamico was assigned to

405 Callitrichinae (Table 4). In the case of Nuciruptor (F11) and Cebupithecia (F12), the occlusal

406 views in both species were relatively rounded, with a slightly rectangular alignment of cusps, and 
407 buccally oriented, which resembles the condition in most extant Pitheciinae. Moreover, the LDA

408 indicated that Cebupithecia and Nuciruptor had a close affinity with the Pitheciidae clade (Table

409 4). However, despite the two neotypes clustered close to the pitheciids, they were not placed into

410 the extant species range (except Nuciruptor on $\mathrm{M}_{2}$ ) (Fig. 2a). Several studies have suggested

411 that, although there are important characteristics that have been associated with the living taxa,

412 both fossils should be considered stem pitheciines (Meldrum and Kay, 1997; Kay et al., 2013;

413 Kay, 2014).

414 The sister relationship between Stirtonia and Alouatta was classified in the LDA with a

$41599.9 \%$ probability for $\mathrm{M}_{1}$ and $94.0 \%$ for $\mathrm{M}_{2}$. Likewise, the PCA showed that Stirtonia was placed

416 close to howler monkeys (Figs. 2a and 3a). However, differences between Stirtonia and Alouatta

417 were mainly seen in the occlusal polygon of $\mathrm{M}_{2}$. The metaconid of Stirtonia was located near the

418 protoconid and the ectoconid was distolingually inclined, somewhat similar to the Cebuella

419 configuration. This relationship was reflected in the high percentage of probability at the

420 subfamily level, Callitrichinae (Table 5).

421 Finally, Xenothrix (F13), the Caribbean platyrrhine form, has been allied with pitheciids

422 (Rosenberger, 2002; Horovitz and MacPhee, 1999). In the LDA, Xenothrix was mainly attributed

423 to pitheciids, but at the genus level, it was assigned to Callithrix (Table 4). Thus, some

424 resemblance with marmosets could be interpreted as convergent evolution. However, the

425 relationship between Xenothrix and pitheciids was highly uncertain, given that its molar

426 morphology (especially the occlusal configuration) differs from that of the pitheciids. It is likely

427 that Xenothrix could be a single branch that evolved independently of crown platyrrhines, as was

428 suggested by some investigations that proposed an early Antillen arrival (Iturralde-Vinent and 
429 MacPhee, 1999; MacPhee and Iturralde-Vinent, 1995; MacPhee and Horovitz, 2004; Kay et al., $430 \quad 2011$; Kay, 2014).

431 The slow rate of phenotypic changes on molar shapes suggests that morphological stasis

432 (different concept from long lineages hypothesis) explains the low interspecific variation

433 between extinct and extant linages and between Early Miocene platyrrhines (including $P$.

434 sylviae) and forms from La Venta. This small phenotypic variation could be due to development 435 and functional constraints, given the role in occlusion and mastication (Gómez-Robles and Polly 436 2012) and the reduced dietary diversification in platyrrhines. This ecological constraint may be 437 related to the fact that the phenotypic adaptation of main platyrrhine families could have 438 happened in Amazon rainforest (Jameson Kiesling et al. 2014). Following an African origin 439 scenario, and taking into account the phenotypic similarity of the most recent discovered and 440 oldest fossil found in Peru, Perupithecus (Bond et al., 2015), it is likely that the ancestor of 441 extant platyrrhines could have exhibited a Callimico-like molar shape. We also observed that 442 Saguinus and Callicebus were the main assigned groups for Patagonian fossils by the LDA, 443 which suggests that there were both Callicebus-like and Saguinus-like morphologies in early 444 stem platyrrhines, dispite extant Saguinus might not represent an early branch according to 445 molecular evidence. Currently, Callicebus and Saguinus present relatively high diversity of 446 species and geographic range (Rylands and Mittermeier 2009). The Callicebus and Saguinus 447 species richness probably are related to expansion and diversification of both clades in the 448 Amazon basin, during the period of platyrrhine evolution (Ayres and Clutton-Brock, 1992; 449 Boubli et al., 2015). Thus, it is feasible that Callicebus, as well as Saguinus, molar shape would 450 be an ancestral precursor for the existing forms. Moreover, the Middle Miocene platyrrhines 
451 indicate continuity in molar shape pattern with the early fossils, incorporating also new molar

452 shapes not observed in the Patagonian forms: the Alouatta-like and the Pitheciinae-like forms.

453

454

455

CONCLUSIONS

456

This study develops a dental model based on molar shapes of $\mathrm{M}_{1}$ and $\mathrm{M}_{2}$ to explore

457 phenotypic variation in extinct and extanct platyrrhines. Our results showed that morphological

458 stasis explains the low phenotypic changes in extinct and exctant platyrrhine, probably due to the

459 ecological constraint, causing by phenotypic adaptation of platyrrhine in a relative narrow

460 ecological niche. Early and Middle Miocene platyrrhines shared a relative similar shape pattern,

461 while other patterns as Alouatta-like and Pitheciinae-like were incorpored in the Colombian

462 fossils. The relation between both fossil samples could be due to: 1. All platyrrhine molar shapes

463 share a primitive retention of the ancestral state. 2 . An early divergence between two parallel

464 shapes; a Callicebus-like and a Saguinus-like, which would be the ancestral precursors to all

465 other forms. 3. A Callicebus-like and Saguinus-like morphology have also been seen in the early

466 stem platyrrhines.

468 ACKNOWLEDGEMENTS

469 We thank the curators and institutions for allowing us access to specimens and resources:

470 Mario de Vivo and Juliana Gualda Barros (Museu de Zoologia Universidade de São Paulo),

471 Leandro de Oliveira Salles, and we are especially grateful to Sergio Maia Vaz, who supported us

472 with data acquisition (Museu Nacional do Rio de Janeiro). We also thank Mark Teaford and 
473 Kenneth Glander for allowimg us access to howler monkeys tooth molds from Hacienda La

474 Pacífica (Costa Rica). We also thank Katarzyna Górka for helping in the teeth molding. 


\section{REFERENCES}

476 Adams DC, Rohlf FJ, Slice D. 2004. Geometric morphometrics: ten years of progress following 477 the 'revolution'. Italian Journal of Zoology 71: 5-16.

478 Adams DC, Berns CM, Kozak KH, Wiens JJ. 2009. Are rates of species diversification 479 correlated with rates of morphological evolution? Proceedings of the Royal Society B: Biological 480 Sciences 276: 2729-2738.

481 Ayres JM, Clutton-Brock TH. 1992. River boundaries and species range size in Amazonian 482 primates. The American Naturalist 140: 531-537.

483 Bailey SE. 2004. A morphometric analysis of maxillary molar crowns of Middle-Late 484 Pleistocene hominins. Journal of Human Evolution 47: 183-198.

485 Benefit BR. 1993. The permanent dentition and phylogenetic position of Victoriapithecus from 486 Maboko Island, Kenya. Journal of Human Evolution 25: 83-172.

487 Bond M, Tejedor MF, Campbell KE, Chornogubsky L, Novo N, Goin F. 2015. Eocene primates 488 of South America and the African origins of New World monkeys. Nature 489 doi:10.1038/nature14120

490 Bookstein FL. 1991. Morphometric tools for landmark data. Cambridge: Cambridge University 491 Press.

492 Boubli JP, Ribas C, Lynch Alfaro J, da Silva MNF, Pinho GM, Farias IP. 2015. Spatial and 493 temporal patterns of diversification in the Amazon: a test of the riverine hypothesis for all 494 diurnal primates of Rio Negro and Rio Branco in Brazil. Molecular Phylogenetics and Evolution 49582 (PB): 400-412.

496 Cardini A, Elton S. 2008. Does the skull carry a phylogenetic signal? Evolution and modularity 497 in the guenons. Biological Journal of the Linnean Society 93: 813-834.

498 Chatterjee HJ, Ho S, Barnes I, Groves C. 2009. Estimating the phylogeny and divergence times 499 of primates using a supermatrix approach. Evolutionary Biology 9: 259. 
500 Collard M, Wood B. 2000. How reliable are human phylogenetic hypotheses? Proceedings of the 501 National Academy of Sciences 97: 5003-5006.

502 Cooke SB. 2011. Paleodiet of extinct platyrrhines with emphasis on the Caribbean forms: three503 dimensional geometric morphometrics of mandibular second molars. The Anatomical Record 504 294(12): 2073-91.

505 Cooke SB, Rosenberger AL, Turvey S. 2011. An extinct monkey from Haiti and the origins of 506 the Greater Antillean primates. Proceedings of the National Academy of Sciences 108(7): 2699507704.

508 Goodman M, Porter CA, Czelusniak J, Page SL, Schneider H, Shoshani J, Gunnell G, Groves 509 CP. 1998. Toward a phylogenetic classification of primates based on DNA evidence 510 complemented by fossil evidence. Molecular Phylogenetics and Evolution 9: 585-598.

511 Fleagle JG. 1990. New fossil platyrrhines from the Pinturas Formation, southern Argentina. 512 Journal of Human Evolution 19: 61-85.

513 Fleagle JG, Kay RF. 1997. Platyrrhines, catarrhines and the fossil record. In: Kinzey WG, ed. 514 New World Primates: Ecology, Evolution and Behaviour. New York: Aldine, 3-24.

515 Fleagle JG, Tejedor MF. 2002. Early platyrrhines of southern South America. In: Hartwig WC, 516 ed. The primate fossil record. Cambridge: Cambridge University Press, 161-173.

517 Fleagle JG, Powers DW, Conroy GC, Watters JP. 1987. New fossil platyrrhines from Santa Cruz 518 Province, Argentina. Folia Primatologica 48: 65-77.

519 Flynn JJ, Guerrero J, Swisher III CC.1997. Geochronology of the Honda Group. In: Kay RF, 520 Madden RH, Cifelli RL, Flynn JJ, ed. Vertebrate Paleontology in the Neotropics. Washington, 521 D.C: Smithsonian Institution Press, 44-60.

522 Galbany J, Martínez LM, Pérez-Pérez A. 2004. Tooth replication techniques, SEM imaging and 523 microwear analysis in Primates: methodological obstacles. Anthropologie XLII/. 1: 5-12. 
524 Galbany J, Estebaranz F, Martínez LM, Romero A, De Juan J, Turbón D, Pérez-Pérez A. 2006.

525 Comparative analysis of dental enamel polyvinylsiloxane impression and polyurethane casting

526 methods for SEM research. Microscopy Research and Technique 69(4): 246-252.

527 Gamarra B, Nova Delgado M, Romero A, Galbany J \& Pérez-Pérez A (2016, accepted)

528 Phylogenetic signal in molar dental shape of extant and fossil catarrhine primates. Journal of

529 Human Evolution

530 Gómez-Robles A, Polly PD. 2012. Morphological integration in the hominin dentition:

531 evolutionary, developmental, and functional factors. Evolution 66: 1024-1043.

532 Gómez-Robles A, Martinón-Torres M, Bermúdez de Castro JM, Margvelashvili A, Bastir M, 533 Arsuaga A., Pérez-Pérez A, Estebaranz F, Martínez LM. 2007. A geometric morphometric 534 analysis of hominin upper first molar shape. Journal of Human Evolution 53: 272-285.

535 Gómez-Robles A, Martinón-Torres M, Bermúdez de Castro JM, Prado L, Sarmiento S, Arsuaga 536 JL. 2008. Geometric morphometric analysis of the crown morphology of the lower first premolar 537 of hominins, with special attention to Pleistocene Homo. Journal of Human Evolution 55: 627538638.

539 Gómez-Robles A, Martinón-Torres M, Bermúdez de Castro JM, Prado L, Arsuaga JL. 2011. A

540 geometric morphometric analysis of hominin upper premolars: shape variation and

541 morphological integration. Journal of Human Evolution 61: 688-702.

542 Goodall C. 1991. Procrustes methods in the statistical analysis of shape. J. R. Proceedings of the 543 Royal Society B: Biological Sciences 53: 285-339.

544 Groves CP. 2005. Order primates. In: Wilson DE, Reeder DM, ed. Mammal Species of the

545 World: a Taxonomic and Geographic Reference. Johns Hopkins University Press, 111-184.

546 Hershkovitz P. 1970 Notes on Tertiary platyrrhine monkeys and description of a new genus from 547 the late Miocene of Colombia. Folia Primatologica 12: 1-37.

548 Hodgson JA, Sterner KN, Matthews LJ, Burrel 1AS, Rachana AJ, Raaum RL, Stewart CB, 549 Disotell TR. 2009. Successive radiations, not stasis, in the South American primate fauna. 550 Proceedings of the National Academy of Sciences 106: 5534-5539 
551 Horovitz I, MacPhee RD.1999. The quaternary cuban platyrrhine Paralouatta varonai and the 552 origin of Antillean monkeys. Journal of Human Evolution 36(1): 33-68.

553 Iturralde-Vinent M, MacPhee RD. 1999. Paleogeography of the Caribbean region: Implications 554 for Cenozoic biogeography. Bulletin of the American Museum of Natural History 238: 1-95.

555 Jameson Kiesling NM, Yi SV, Sperone G, Wildman DE. 2014. The tempo and mode of New 556 World monkey evolution and biogeography in the context of phylogenomic analysis. Molecular 557 Phylogenetics and Evolution http://dx.doi.org/10.1016/j.ympev.2014.03.027

558 Jernvall J, Jung HS. 2000. Genotype, phenotype, and developmental biology of molar tooth 559 characters. Yearbook of Physical Anthropology 43: 171-190.

560 Kay RF. 1990. The phyletic relationships of extant and fossil Pitheciinae (Platyrrhini, 561 Anthropoidea). Journal of Human Evolution 19: 175-208.

562 Kay RF. 2010. A new primate from the Early Miocene of Gran Barranca, Chubut Province, 563 Argentina: paleoecological implications. In: Madden RH, Vucetich G, Carlini AA, Kay RF, ed. 564 The paleontology of Gran Barranca: evolution and environmental change through the Middle 565 Cenozoic of Patagonia. Cambridge: Cambridge University Press, 220-239.

566 Kay RF. 2014. Biogeography in deep time: What do phylogenetics, geology, and paleoclimate 567 tell us about early platyrrhine evolution? Molecular Phylogenetics and Evolution 568 http://dx.doi.org/10.1016/j.ympev.2013.12.002

569 Kay RF, Frailey CD. 1993. Large fossil platyrrhines from the Río Acre fauna, Late Miocene, 570 western Amazonia. Journal of Human Evolution 25: 319-327.

571 Kay RF, Cozzuol MA. 2006. New platyrrhine monkeys from the Solimoes Formation (late 572 Miocene, Acre State, Brazil). Journal of Human Evolution 50: 673-686.

573 Kay RF, Fleagle JG. 2010. Stem taxa, homoplasy, long lineages and the phylogenetic position of 574 Dolichocebus. Journal of Human Evolution 59: 218-222.

575 Kay RF, Madden RH, Plavcan JM, Cifelli RL, Guerrero-Diaz J. 1987. Stirtonia victoriae, a new 576 species of Miocene Colombian primate. Journal of Human Evolution 16: 173-196. 
577 Kay RF, Williams BA, Ross CF, Takai M, Shigehara N. 2004. Anthropoid origins: a

578 phylogenetic analysis. In: Ross CF, Kay RF, ed. Anthropoid Origins: New Visions. New York:

579 Kluwer/Plenum, 91-136.

580 Kay RF, Fleage JG, Mitchell TRT, Colbert MW, Bown TM, Powers DW. 2008. The anatomy of

581 Dolichocebus gaimanensis, a primitive platyrrhine monkey from Argentina. Journal of Human

582 Evolution 54, 323-382.

583 Kay RF, Hunt KD, Beeker CD, Conrad GW, Johnson CC, Keller J. 2011. Priliminary notes on a 584 newly discovered skull of the extinct monkey Antillothrix from Hispaniola and the origin of the 585 Greater Antillean monkeys. Journal of Human Evolution 60: 124-128.

586 Kay RF, Meldrum DJ, Takai M. 2013. Pitheciidae and other platyrrhine seed predators. In:

587 Veiga L, Barnett A, Ferrari S, Norconk M. ed. Evolutionary biology and conservation of titis, 588 sakis and uacaris. Cambridge: Cambridge University Press, 3-12.

589 Hodgson JA, Sterner KN, Matthews LJ, Burrel 1AS, Rachana AJ, Raaum RL, Stewart CB, Disotell TR, 590 2009. Successive radiations, not stasis, in the South American primate fauna. Proceedings of the National 591 Academy of Sciences 106: 5534-5539

592 Kinzey WG. 1992. Dietary and dental adaptations in the Pitheciinae. American Journal of 593 Physical Anthropology 88: 499-514.

594 Klingenberg CP. 2011. MorphoJ. Faculty of Life Sciences. Manchester, UK: University of 595 Manchester.

596 Klingenberg CP, Gidaszewski NA, 2010. Testing and quantifying phylogenetic signals and 597 homoplasy in morphometric data. Systematic Biology 59: 245-261.

598 Kovarovic K, Aiello LC, Cardini A, Lockwood CA. 2011. Discriminant functions analyses in 599 archaeology: Are classification rates too good to be true?. Journal of Archaeological Science 38: $6003006-3018$.

601 MacPhee RDE, Iturralde-Vinent M. 1995. Origin of the Greater Antillean land mammal fauna: 602 New Tertiary fossils from Cuba and Puerto Rico. American Museum Novitates 3141: 1-31 
603 MacPhee RDE, Horovitz I. 2004. New craniodental remains of the Quaternary Jamaican monkey 604 Xenothrix mcgregori (Xenotrichini, Callicebinae, Pitheciidae), with a reconsideration of the 605 Aotus hypothesis. American Museum Novitates 3434: 1-51.

606 Martinón-Torres M, Bastir M, Bermudez de Castro JM, Gómez-Robles A, Sarmiento S, Muela 607 A, Arsuaga JL. 2006. Hominin lower second premolar morphology: evolutionary inferences 608 through geometric morphometric analysis. Journal of Human Evolution 50, 523-533.

609 Meldrum DJ, Kay RF. 1997. Nuciruptor rubricae, a new pitheciin seed predator from the 610 Miocene of Colombia. American Journal of Physical Anthropology 102: 407-427.

611 Miller ER, Simons EL. 1997. Dentition of Proteopithecus sylviae, an archaic anthropoid from 612 the Fayum, Egypt. Proceedings of the National Academy of Sciences 94: 13760-13764.

613 Nova Delgado M, Gamarra B, Nadal J, Mercadal O, Olesti O, Guàrdia J, Pérez-Pérez A, Galbany 614 J. 2015a. Dental shape variability in cercopithecoid primates: A model for the taxonomic 615 attribution of macaques from roman archaeological contexts. Folia Primatologica 85: 361-378.

616 Nova Delgado M, Galbany J, Górka K, Pérez-Pérez A. 2015b. Taxonomic Implications of Molar 617 Morphology Variability in Capuchins. International Journal of Primatology 618 doi:10.1007/s10764-015-9850-4

619 Oliveira FB, Molina ECE, Marroig G. 2009. Paleogeography of the South Atlantic: a route for 620 primates and rodents into the New World? In: Garber PA, Estrada A, Bicca-Marques JC, 621 Heymann EW, Strier K, ed. South American Primates: Comparative Perspectives in the Study of 622 Behavior Ecology and Conservation. New York: Springer, 55-68.

623 Opazo JC, Wildman DE, Prychitko T, Johnson RM, Goodman M. 2006.Phylogenetic 624 relationships and divergence times among New World monkeys (Platyrrhini, Primates). 625 Molecular Phylogenetics and Evolution 40: 274-280.

626 Osterholz M, Walter L, Roos C. 2009. Retropositional events consolidate the branching order among 627 New World monkey genera. Molecular Phylogenetics and Evolution: 507-513. 
629 Perelman P, Johnson WE, Roos C, Seuanez HN, Horvath JE, Moreira MA, Kessing B, Pontius J, 630 Roelke M, Rumpler Y, Schneider MP, Silva A, O’Brien SJ, Pecon-Slattery J. 2011. A molecular 631 phylogeny of living primates. PLOS Genetics 3, e1001342.

632 Perez SI, Tejedor MF, Novo NM, Aristide L. 2013. Divergence times and the evolutionary 633 radiation of New World monkeys (Platyrrhini, Primates): an analysis of fossil and molecular 634 data. PLoS One 8(6), e68029. doi:10.1371/journal.pone.0068029

635 Rohlf FJ. 1999. Shape statistics: Procrustes superimpositions and tangent spaces. Journal of 636 Classification16: 197-223.

637 Rohlf FJ. 2004. TpsDig, version 1.40. TpsSeries. Department of Ecology and Evolution, SUNY, 638 Stony Brook, New York.

639 Rohlf FJ. 2005. Geometric morphometrics simplified: review of "Geometric Morphometrics for 640 Biologists: A Primer." Trends in Ecology and Evolution 20: 13-14.

641 Rohlf FJ, Marcus LE. 1993. A revolution in morphometrics. Trends in Ecology and Evolution 8: $642 \quad 129-132$.

643 Rohlf FJ, Slice D. 1990. Extensions of the Procrustes method for the optimal superimposition of 644 landmarks. Systematic Zoology 39: 40-59.

645 Rosenberger AL. 1979. Cranial anatomy and implications of Dolichocebus gaimanensis, a late 646 Oligocene ceboid primate. Nature 279: 416-418.

647 Rosenberger AL. 1980. Gradistic views and adaptive radiation of platyrrhine primates. 648 Zeitschrift für Morphologie und Anthropologie 71: 157-163.

649 Rosenberger AL. 1981. Systematics: the higher taxa. In: Coimbra-Filho AF, Mittermeier RA, ed. 650 Ecology and behavior of neotropical primates. Rio de Janeiro:Academia Brasileira de Ciencias, $6519-28$.

652 Rosenberger AL. 1984. Fossil New World monkeys dispute the molecular clock. Journal of 653 Human Evolution 13: 737-742. 
654 Rosenberger AL. 2002. Platyrrhine paleontology and systematics: the paradigm shifts. In:

655 Hartwig WC, ed. The primate fossil record. Cambridge: Cambridge University Press, 151-159.

656 Rosenberger AL. 2010. Platyrrhines, PAUP, parallelism, and the Long Lineage Hypothesis: A 657 replay to Kay et al. (2008). Journal of Human Evolution 59: 214-217.

658 Rosenberger AL. 2011. Evolutionary morphology, platyrrhine evolution, and systematics. The 659 Anatomical Record 294: 1955-1974.

660 Rosenberger AL, Setoguchi T, Shigehara N. 1990a. The fossil record of callitrichine primates. 661 Journal of Human Evolution 19: 209-236.

662 Rosenberger AL, Setoguchi T, Shigehara N. 1990b. Towards a paleontology of the New World 663 callitrichine primates. Journal of Human Evolution 19: 209-236.

664 Rosenberger AL, Hartwig WC, Takai M, Setoguchi T, Shigehara N. 1991a. Dental variability in 665 Saimiri and the taxonomic status of Neosaimiri fieldsi, an early squirrel monkey from La Venta, 666 Colombia. International Journal of Primatology 12: 291-302.

667 Rosenberger AL, Setoguchi T, Hartwig WC. 1991b. Laventiana annectens, new genus and 668 species: fossil evidence for the origins of callitrichine New World monkeys. Proceedings of the 669 National Academy of Sciences 88: 2137-2140.

670 Rosenberger AL. Tejedor MF, Cooke SB, Halenar L, Pekkar S. 2009. Platyrrhine 671 ecophylogenetics, past and present. In: Garber P, Estrada A, Bicca-Marques JC, Heymann EW, 672 Strier KB, ed. South American primates: comparative perspectives in the study of behavior, 673 ecology and conservation. New York: Springer, 69-113.

674 Rylands AB, Mittermeier RA. 2009. The diversity of the New World primates (Platyrrhini). In: 675 Garber P, Estrada A, Bicca-Marques JC, Heymann EW, Strier KB, ed. South American primates: 676 comparative perspectives in the study of behavior, ecology and conservation. New York: 677 Springer, 23-54.

678 Setoguchi T, Rosenberger AL. 1987. A fossil owl monkey from La Venta, Colombia. Nature 679 326: 692-694. 
680 Singleton M, Rosenberger AL, Robinson C, O’Neill R. 2011. Allometric and metameric shape 681 variation in Pan mandibular molars: a digital morphometric analysis. The Anatomical Record 682 294: 322-334.

683 Slice DE. (Ed.), 2005. Modern Morphometrics in Physical Anthropology. Kluwer 684 Academic/Plenum Publishers, New York.

685 Slice DE. 2007. Geometric morphometrics. Annual Review of Anthropology 36: 261-281.

686 SPSS, Inc., 2006. SPSS 15.0 Command Syntax Reference. SPSS Inc., Chicago IL.

687 Swindler DR. 2002. Primate dentition: An introduction to the teeth of non-human primates. 688 Cambridge University Press, Cambridge

689 Takai M. 1994. New specimens of Neosaimiri fieldsi from La Venta, Colombia: a Middle 690 Miocene ancestor of the living squirrel monkeys. Journal of Human Evolution 27: 329-360.

691 Takai M. Anaya F, Shigehara N, Setoguchi T. 2000. New fossil materials of the earliest New 692 World monkey, Branisella boliviana, and the problem of platyrrhine origins. American Journal 693 of Physical Anthropology 111: 263-281.

694 Takai M. Nishimura T, Shigehara N, Setoguchi T. 2009. Meaning of the canine sexual 695 dimorphism in fossil owl monkey Aotus dindensis, from the middle Miocene of La Venta, 696 Colombia. In: Koppe T, Meyer G, Alt KW, ed. Comparative Dental Morphology. Front Oral 697 Biology. Karger, Basel 13, 55-59.

698 Tejedor MF. 2003. New fossil primate from Chile. Journal of Human Evolution 44: 515-520.

699 Tejedor MF. 2005. New fossil platyrrhine from Argentina. Folia Primatologica 76: 146-150.

700 Tejedor MF. 2008. The origin and evolution of Neotropical primates. Arquivos do Museu 701 Nacional do Rio de Janeiro 66(1): 251-269.

702 Tejedor MF. 2013. Sistemática, evolución y paleobiogeografía de los primates Platyrrhini. 703 Revista del Museo de La Plata. Sección Zoología 20: 20-39. 
704 Tejedor MF, Rosenberger AL. 2008. A neotype for Homunculus patagonicus Ameghino, 1891, 705 and a new interpretation of the taxon. Paleoanthropology 2008: 68-82.

706 Wildman, D.E., Jameson, N.M., Opazo, J.C., Yi, S.V., 2009. A fully resolved genus level phylogeny of

707 Neotropical primates (Platyrrhini). Molecular Phylogenetics and Evolution 53: 694-702

708 Wilkinson RD, Steiper ME, Soligo C, Martin RD, Yang Z, Tavaré S. 2011. Dating primate

709 divergences through an integrated analysis of palaeontological and molecular data. Systematic

710 Zoology 60: 16-31.

711 Zelditch ML, Swiderski DL, Sheets HD, Fink WL. 2004. Geometric morphometrics for

712 biologists: San Diego, California: Elsevier Academic Press. 
Table 1: List of fossils used in the study.

$\begin{array}{ll}\text { Fossils } & \text { Location }\end{array}$

reference
Fayum, Egypt

$33.9-28.4^{\mathrm{a}}$

stem anthropoid ${ }^{\mathrm{b}}$

(1997)

\begin{tabular}{|c|c|c|c|}
\hline F2 Soriacebus spp. & $\begin{array}{l}\text { Pinturas Formation, } \\
\text { Santa Cruz Province, } \\
\text { Argentina }\end{array}$ & $17^{\mathrm{c}}$ & $\begin{array}{l}\text { stem platyrrhine } / \\
\text { Pitheciidae }^{\mathrm{e}}\end{array}$ \\
\hline F3 Dolichocebus gaimanesis & $\begin{array}{l}\text { Gaiman, } \\
\text { Chubut Province, } \\
\text { Argentina }\end{array}$ & $20^{\mathrm{f}}$ & $\begin{array}{l}\text { stem platyrhine/ } \\
\text { sister to Saimiri }\end{array}$ \\
\hline \multirow{2}{*}{$\begin{array}{l}\text { F4 Homunculus spp. } \\
\text { Rosemberger }\end{array}$} & Santa Cruz Formation, & $16.5^{\mathrm{h}}$ & stem platyrrhine/ \\
\hline & $\begin{array}{l}\text { Santa Cruz Province, } \\
\text { Argentina }\end{array}$ & & Pitheciidae \\
\hline F5 Carlocebus spp. & $\begin{array}{l}\text { Pinturas Formation, } \\
\text { Santa Cruz Province, } \\
\text { Argentina }\end{array}$ & $18-19^{\mathrm{i}}$ & $\begin{array}{l}\text { stem platyrrhine/ } \\
\text { Pitheciidae }\end{array}$ \\
\hline F6 Neosaimiri fieldsi & $\begin{array}{l}\text { La Venta, Huila, } \\
\text { Colombia }\end{array}$ & \multicolumn{2}{|c|}{$13.5-11.8^{\mathrm{j}}$ sister to Saimirik ${ }^{\mathrm{k}}$} \\
\hline F7 Laventiana annectens & La Venta, Huila, & \multicolumn{2}{|c|}{$13.5-11.8$ sister to Saimiri/ } \\
\hline
\end{tabular}

CGM 42209; Miller and Simons

MACN-SC $2^{1}$, MACN-SC $5^{2}$ MPM-PV 363; Tejedor (2005)

MPEF 5146; Kay et al. (2008)

MACN-A5969; Tejedor and

MACN-SC 266; Fleagle (1990)

IGM-KU 890294, IGM-KU 890195, UCMP 392056, IGM-KU 890027, IGM-KU 39034 ${ }^{8}$, IGM-KU 89053', IGM-KU 8913010; Takai (1994)

IGM-KU 880; Rosemberger et al., 
Colombia

F8 Mohanamico hershkouitzi

F9 Aotus dindensis

F10 Stirtonia spp.

F11 Nuciruptor rubricae (1997)

F12 Cebupithecia sarmientoni (1997)

F13 Xenothrix macgregori

\section{La Venta, Huila, Colombia}

La Venta, Huila, Colombia

La Venta, Huila,

La Venta, Huila,

Colombia

La Venta, Huila,

Colombia

Jamaica synonymy with

Neosaimiri ${ }^{1}$

(1991b)

$13.5-11.8$ sister to Callimico $^{\mathrm{m}}$

\section{$13.5-11.8$ sister to Aotus ${ }^{\mathrm{n}}$ / coespecific with \\ Mohanamico ${ }^{\circ}$}

$13.5-11.8$ sister to Alouatta $^{\mathrm{p}}$

13.5 -11.8 Pitheciidaeq/

stem Pitheciinae ${ }^{\mathrm{r}}$

13.5 -11.8 Pitheciidae/ stem Pitheciinae

Holocenes stem platyrhine/ retaded to Callicebus ${ }^{t}$
IGM 181500; Kay (1990)

IGM-KU 8601; Kay (1990)

UCPM 38989; Kay et al. (1987)

IGM 251074; Meldrum and Kay

UCMP 38762; Meldrum and Kay

AMNHM 148198; MacPhee and Horovitz (2004)

References used in the table: Miller and Simons 1997a; Kay 1990 ; Fleagle et al., 1987c; (Kay, 2010; 2014; Kay and Fleagle, 2010;

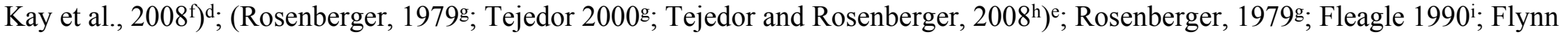

et al., 1997j; Rosenberger et al., 1991b 
Rosenberger, 1987; Takai et al., 2009)n; Meldrum y Kay, 1997o,q; (e g., Hershkovitz P 1970; Kay et al., 1987)p; Cooke et al., 2011;

771 MacPhee and Horovitz 2004

772 Institutional abbreviations: CGM: Cairo Geological Museum; MPM-PV: Museo Regional Provincial Padre Manuel Jesús Molina, Río

Gallegos, Argentina; MPEF: Museo Paleontológico E. Feruglio, Trelew, Chubut Province, Argentina; MACN, MACN-SC/A: Museo Argentino de Ciencias Naturales "Bernardino Rivadavia," Buenos Aires, Argentina; SC/A denotes locality; IGM, IGM-KU: Museo

777 American Museum of Natural History. 
778 Table 2 List of the specimens included in this analysis of $\mathrm{M}_{1}$ and $\mathrm{M}_{2}$. The Subfamily-level

779 classification was proposed by Groves (2005).

780 Genus / species $\quad \mathbf{M}_{1-2} \quad$ Collection $^{\mathrm{a}}$

781 Subfamily: Cebinae

782 Cebus (gracile capuchins)

7831 C. albifrons

9 MZUSP, MNRJ

7842 C. olivaceus

$6 \quad$ MNRJ

785 Sapajus (robust capuchins)

7863 S. apella

$14 \quad$ MZUSP

7874 S. libidinosus

$15 \quad$ MNRJ

7885 S. nigritus

$15 \quad$ MNRJ

789

6 S. robustus

15

MNRJ

7907 S. xanthosternos

$7 \quad$ MNRJ

791 Subfamily: Samiriinae

792 Saimiri (squirrel monkeys)

7938 S. boliviensis

17 MZUSP, MNRJ

7949 S. sciureus

25 MZUSP, MNRJ

79510 S. ustus

$18 \quad$ MZUSP, MNRJ

79611 S. vanzolinii

$8 \quad$ MNRJ

797 Subfamily: Callitrichinae

798 Callithrix (marmosets from Atlantic Forest)

799

12 C. aurita

11

MNRJ

800

13 C. geoffroyi

15

MNRJ 


$\begin{array}{llcl}801 & \mathbf{1 4} \text { C. jacchus } & 21 & \text { MZUSP } \\ 802 & \mathbf{1 5} \text { C. } \text { kuhlii } & 20 & \text { MNRJ } \\ 803 & \mathbf{1 6} \text { C. penicillata } & 14 & \text { MNRJ } \\ 804 & \text { Mico (marmosets from Amazon) } & & \\ 805 & \mathbf{1 7} \text { M. argentata } & 21 & \text { MZUSP, MNRJ } \\ 806 & \mathbf{1 8} \text { M. chrysoleuca } & 16 & \text { MZUSP, MNRJ } \\ 807 & \mathbf{1 9} \text { M. emiliae } & 6 & \text { MZUSP } \\ 808 & \mathbf{2 0} \text { M. humeralifer } & 16 & \text { MZUSP } \\ 809 & \mathbf{2 1} \text { M. melanurus } & 8 & \text { MZUSP, MNRJ }\end{array}$

810 Cebuella (pygmy marmoset)

81122 C. pygmaea

MZUSP

812 Callimico (goeldi's marmoset)

81323 C. goeldii

MZUSP

814 Leontopithecus (lion tamarins)

81524 L. chrysomelas

MZUSP, MNRJ

81625 L. rosalia

MZUSP, MNRJ

817 Saguinus (tamarins)

81826 S. fuscicollis

$13 \quad$ MZUSP

81927 S. imperator

$10 \quad$ MZUSP

82028 S. labiatus

9 MZUSP, MNRJ

82129 S. midas

22

MZUSP, MNRJ

82230 S. mystax

13

MZUSP, MNRJ

82331 S. niger

14

$\mathrm{M}_{2} \mathrm{NRJ}$ 
824 Subfamily: Aotinae

825 Aotus (owl or night monkeys)

82631 A. azarae

82732 A. nigriceps

82833 A. trivirgatus

829 Subfamily: Callicebinae

830 Callicebus (titi monkeys)

83134 C. bernhardi

83235 C. cupreus

83336 C. hoffmannsi

83437 C. moloch

83538 C. nigrifrons

83639 C. personatus

837 Subfamily: Pitheciinae

838 Cacajao (uakaris)

83940 C. calvus

84041 C. melanocephalus

841 Chiropotes (bearded sakis)

84242 C. albinasus

84343 C. satanas

844 Pithecia (sakis)

84544 P. irrorata

84645 P. monachus
MZUSP
MZUSP, MNRJ

MZUSP, MNRJ

5

MNRJ

14 MZUSP, MNRJ

$12 \quad$ MNRJ

16 MZUSP, MNRJ

8

MNRJ

16

MZUSP, MNRJ
14 MZUSP, MNRJ

9

MZUSP, MNRJ

18 MZUSP, MNRJ

15 MZUSP, MNRJ

17 MZUSP, MNRJ

$7 \quad$ MZUSP, MNRJ 
84746 P. pithecia

16

MZUSP, MNRJ

848

849 Subfamily: Atelinae

850 Lagothrix (woolly monkeys)

85147 L. cana

7

MNRJ

85248 L. lagotricha

8

MZUSP

853 Brachyteles (muriquis)

85449 B. arachoides

MZUSP, MNRJ

85550 B. hypoxanthus

5

MNRJ

856 Ateles (spider monkeys)

85751 A. belzebuth

2

RBINS

858

52 A. chamek

15

MNRJ

859

53 A. marginatus

20

MZUSP

860 Subfamily: Alouatinae

861 Alouatta (howler monkeys)

86254 A. belzebul

15

MZUSP

86355 A. caraya

MZUSP, MNRJ

86456 A. discolor

$10 \quad$ MNRJ

86557 A. guariba

5

MZUSP, MNRJ

86658 A. g. clamitas $\dagger$

15

MNRJ

86759 A. nigerrima

10

MNRJ

86860 A. palliata

15

HLP

869

61 A. seniculus

15

MZUSP 
$871 \dagger$ Subspecies of Alouatta guariba

872 a Institutional abbreviations: MZUSP: Museu de Zoologia Universidade de São Paulo (Brazil);

873 MNRJ: Museu Nacional do Rio de Janeiro (Brazil); HLP: Hacienda La Pacífica. 
874 Table 3. Landmarks considered for the geometric morphometrics analysis of dental crown shape.

875

876 Landmark Type Definition

87712 Tip of the distolingual cusp (entoconid)

87822 Tip of the mesiolingual cusp (metaconid)

87932 Tip of the mesiobuccal cusp (protoconid)

88042 Tip of the distobuccal cusp (hypoconid)

88153 Most distal point of the mid mesiodistal line on the crown outline

88262 Point of maximum curvature directly below the entoconid*

88373 Point on the dental crown outline at the lingual groove

88482 Point of maximum curvature directly below the metaconid*

88593 Most mesial point of the mid mesiodistal line on the crown outline

886102 Point of maximum curvature directly below the protoconid*

$88711 \quad 3 \quad$ Point on the dental crown outline at the mesial groove

$88812 \quad 2$ Point of maximum curvature directly below the hypoconid*

889132 Midpoint between the preentocristid and postmetacristid*

890142 Lowest point on the protocristid*

$89115 \quad 2 \quad$ Lowest point on the crista oblique*

$892 *$ Landmarks follow definitions by Cooke (2011) 
893 Table 4. A comparison of platyrrhines at the subfamily level classifications

894

Subfamily by Groves Subfamily by Rosenberger

Genus

(2005)

(2011)

\begin{tabular}{|c|c|c|}
\hline Cebus & \multirow{2}{*}{ Cebinae } & \multirow{3}{*}{ Cebinae } \\
\hline Sapajus & & \\
\hline Saimiri & Saimiriinae & \\
\hline Callithrix & \multirow{6}{*}{ Callitrichinae } & \multirow{6}{*}{ Callitrichinae } \\
\hline Mico & & \\
\hline Cebuella & & \\
\hline Callimico & & \\
\hline Leontopithecus & & \\
\hline Saguinus & & \\
\hline Aotus & Aotinae & \multirow{2}{*}{ Homunculinae } \\
\hline Callicebus & Callicebinae & \\
\hline Cacajao & \multirow{3}{*}{ Pitheciinae } & \multirow{3}{*}{ Pitheciinae } \\
\hline Chiropotes & & \\
\hline Pithecia & & \\
\hline Lagothrix & \multirow{3}{*}{ Atelinae } & \multirow{4}{*}{ Atelinae } \\
\hline Brachyteles & & \\
\hline Ateles & & \\
\hline Alouatta & Alouattinae & \\
\hline
\end{tabular}

895

896 
Table 5. Summary of the LDA, including the percentage of variance for the two discriminant function (DF1 and DF2), the percentage of original grouped cases correctly classified and the percentage of cross-validated. Further, the percentage of probability that each case (fossil) belongs to the predicted group. Family: Pitheciidae, Cebidae, Atelidae; subfamily by Groves (2005) (Subfamily by G): Aotinae, Cebinae, Saimiriinae, Callitrichinae, Pitheciinae, Callicebinae, Atelinae, Alouattinae; subfamily by Rosenberger (2011) (Subfamily by R): Cebinae, Callitrichinae, Pitheciinae, Homunculinae, Atelinae; Genus: The names are listed in Table 2. Soriacebus ${ }^{1,2,3}$ and Neosaimiri ${ }^{4}$, 5, 6, 7, 8,9,10 corresponding to the holotypes numbered on Table 1.

a) $\mathbf{M}_{1}$

\begin{tabular}{|c|c|c|c|c|c|c|c|c|}
\hline & & Fami & $\%$ & Subf & mily by G \% & Subf: & nily by R \% & Genus \% \\
\hline DF1 & & 56.0 & & 50.5 & & 42.4 & & 49.0 \\
\hline DF2 & & 44.0 & & 19.1 & & 29.1 & & 14.2 \\
\hline Classification & & 88.7 & & 91.3 & & 88.2 & & 91.0 \\
\hline Cross-validatio & & 87.4 & & 88.0 & & 85.7 & & 86.3 \\
\hline$\left(\mathbf{M}_{1}\right)$ & Family & $\%$ & Subfamily by & $\%$ & Subfamily by & $\%$ & Genus & $\%$ \\
\hline Proteopithecus & Cebidae & 99.6 & Saimiriinae & 99.2 & Cebinae & 99.9 & Saimiri & 99.3 \\
\hline Soriacebus ${ }^{1}$ & Cebidae & 99.9 & Callitrichinae & 99.9 & Callitrichinae & 99.8 & Saguinus & 89.6 \\
\hline Soriacebus ${ }^{2}$ & Cebidae & 99.1 & Callitrichinae & 76.6 & Callitrichinae & 94.0 & Callithrix & 69.1 \\
\hline Dolichocebus & Cebidae & 86.5 & Callicebinae & 77.9 & Homunculinae & 67.4 & Callicebus & 86.4 \\
\hline
\end{tabular}




\begin{tabular}{|c|c|c|c|c|c|c|c|c|c|}
\hline 914 & Carlocebus & Cebidae & 97.0 & Callitrichinae & 94.2 & Callitrichinae & 83.7 & Callithrix & 87.1 \\
\hline 915 & Neosaimiri ${ }^{4}$ & Pitheciidae & 48.5 & Atelinae & 48.8 & Callitrichinae & 52.2 & Saguinus & 78.7 \\
\hline 916 & Neosaimiri ${ }^{5}$ & Cebidae & 98.4 & Callitrichinae & 97.5 & Callitrichinae & 97.3 & Saguinus & 99.6 \\
\hline 917 & Neosaimiri ${ }^{6}$ & Cebidae & 97.0 & Callitrichinae & 76.5 & Callitrichinae & 94.6 & Saguinus & 72.2 \\
\hline 918 & Laventiana & Atelidae & 94.6 & Atelinae & 44.5 & Atelinae & 94.9 & Callicebus & 53.0 \\
\hline 919 & Mohanamico & Cebidae & 96.2 & Callitrichinae & 87.3 & Callitrichinae & 70.3 & Leontopithecus & 65 \\
\hline 920 & Aotus dindensis & Pitheciidae & 59.0 & Aotinae & 99.7 & Homunculinae & 97.4 & Aotus & 98.7 \\
\hline 921 & Stirtonia & Atelidae & 98.9 & Alouattinae & 99.9 & Atelinae & 98.2 & Alouatta & 99.9 \\
\hline 922 & Nuciruptor & Pitheciidae & 99.7 & Callicebinae & 99.5 & Homunculinae & 83.6 & Callicebus & 63.3 \\
\hline 923 & Cebupithecia & Pitheciidae & 96.5 & Pitheciinae & 92.1 & Pitheciinae & 65.3 & Chiropotes & 59.2 \\
\hline 924 & Xenothrix & Pitheciidae & 75.8 & Callicebinae & 30.5 & Homunculinae & 61.9 & Callithrix & 90.7 \\
\hline
\end{tabular}


DF1

DF2

Classification

Cross-validation

\section{Family\%}

68.3

31.7

89.5

88.2

\section{Subfamily by G \%}

45.6

29.0

93.3

90.6

\section{Subfamily by R \% Genus \%}

47.6

32.8

90.3

89.0
43.5

22.6

88.7

84.7

$\begin{array}{lllllll}\left(M_{2}\right) & \text { Family } & \% & \text { Subfamily by G \% } & \text { Subfamily by R\% } & \text { Genus } & \%\end{array}$

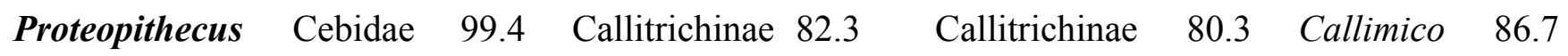

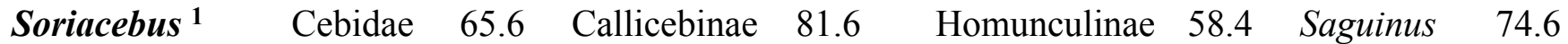

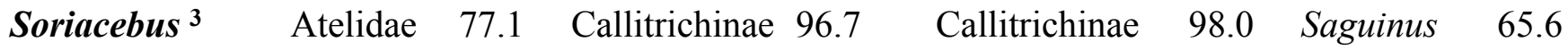

Dolichocebus $\quad$ Cebidae 50.7 Callicebinae $92.6 \quad$ Homunculinae 90.1 Callicebus 92.6

Homunculus Pitheciidae91.4 Callicebinae 93.7 Homunculinae 97.3 Callicebus 99.9

Cebidae $\quad 55.6$ Callitrichinae 58.8

Callitrichinae $\quad 50.4 \quad$ Mico

72.5

Neosaimiri

Cebidae $\quad 98.3$ Callicebinae 92.9

Cebinae

$35.8 \quad$ Callicebus $\quad 67.2$

Neosaimiri $^{8} \quad$ Cebidae

64.9 Callicebinae 61.2

Homunculinae 93.7 Saguinus

65.1

Neosaimiri ${ }^{9}$

Cebidae 99.5 Callitrichinae 61.3

Callitrichinae $51.7 \quad$ Saguinus

92.3

Neosaimiri ${ }^{10}$

Cebidae $\quad 98.9$ Callicebinae 84.6

Callitrichinae 71.9 Saguinus

98.3

Laventiana

Cebidae

99.9 Callitrichinae 99.8

Callitrichinae 99.7 Saguinus

40.8 


$\begin{array}{llllllllll}947 & \text { Mohanamico } & \text { Cebidae } & 97.7 & \text { Callitrichinae } & 94.9 & \text { Callitrichinae } & 94.6 & \text { Saguinus } & 99.9 \\ 948 & \text { Aotus dindensis } & \text { Cebidae } & 84.4 & \text { Callicebinae } & 88.9 & \text { Homunculinae } & 76.1 & \text { Callicebus } & 96.5 \\ 949 & \text { Nuciruptor } & \text { Pithecidae } & 89.7 & \text { Pitheciinae } & 89.7 & \text { Pitheciinae } & 73.0 & \text { Pithecia } & 49.4 \\ 950 & \text { Stirtonia } & \text { Atelidae } & 81.8 & \text { Alouattinae } & 86.0 & \text { Callitrichinae } & 92.1 & \text { Alouatta } & 94.0\end{array}$

951 